\title{
Diurnal temperature fluctuations in an artificial small shallow water body
}

\author{
Adrie F. G. Jacobs • Bert G. Heusinkveld • Aline Kraai • \\ Krijn P. Paaijmans
}

Received: 18 April 2007 /Revised: 23 August 2007 / Accepted: 6 September 2007 / Published online: 10 October 2007

(C) ISB 2007

\begin{abstract}
For aquatic biological processes, diurnal and annual cycles of water temperature are very important to plants as well as to animals and microbes living in the water. An existing one-dimensional model has been extended to simulate the temperature profile within a small water body. A year-round outdoor experiment has been conducted to estimate the model input parameters and to verify the model. Both model simulations and measurements show a strong temperature stratification in the water during daytime. Throughout the night, however, a wellmixed layer starting at the water surface develops. Because the water body is relatively small, it appears that the sediment heat flux has a strong effect on the behaviour of the water temperature throughout the seasons. In spring, the water temperature remains relatively low due to the cold surrounding soil, while in autumn the opposite occurs due to the relatively warm soil. It appears that, in small water bodies, the total amount of incoming long wave radiation is sensitive to the sky view factor. In our experiments, the intensity of precipitation also appears to have a small effect on the stratification of the water temperature.
\end{abstract}

Keywords Shallow water body . Water temperature . Energy budget $\cdot$ Model simulation

A. F. G. Jacobs $(\triangle) \cdot$ B. G. Heusinkveld • A. Kraai K. P. Paaijmans

Meteorology and Air Quality Group, Wageningen University, P.O. Box 47, 6700 AA Wageningen, The Netherlands

e-mail: adrie.jacobs@wur.nl

\section{Introduction}

The growth and development of cold blooded water organisms is strongly affected by temperature. In many ecological models, air temperature or "bulk water" temperature is used as an input parameter. For example, organisms that live close to the water surface in shallow waters, such as the larvae of mosquito species, are exposed to temperatures that differ considerably from the air or bulk water temperature. Simulation studies with mosquito species that act as vectors of malaria have shown that variations in mortality and development of the aquatic stages due to surface water temperature are the most important factor in determining the number of emerging adult mosquitoes (Jetten and Takken 1994a).

Water temperature also affects the development of hydrophytic plants. For example, if the water temperature in an aquatic ecosystem increases, the rate of photosynthesis in the plants also increases. Photosynthesis rates increase up to a temperature of about $32^{\circ} \mathrm{C}$. As the rate of photosynthesis increases, the number of aquatic plants increases. This increase also leads to an increase in the number of plants that die and are decomposed by aerobic bacteria, which consume oxygen in the process (Nicolet et al. 2004; De Meester et al. 2005).

Knowledge of the behaviour of the temperature within shallow waters is also of importance for practical applications in aquaculture. Examples include fish ponds and rice paddies, since a direct relationship exists between the density gradient in water as influenced by temperature and the consequent growth rate of fish or development and growth of rice, respectively (Losordo and Piedrahita 1991; Bouman et al. 1993). Furthermore, the temperature of shallow water is an important factor influencing competition between species. This has already been shown for 
some closely related malaria vector species (Jetten and Takken 1994b). In such circumstances, the incidence of malaria may be closely related to the presence of more or less anthropophilic vector species.

The most important input quantities in natural shallow water bodies during the daytime are the incoming shortand net long-wave radiation, the air temperature and the wind speed. Long-wave radiation is absorbed at the top of the water body, as well as a large part- the so-called nearinfra red - of the incoming short-wave radiation. During the day, this leads to a stable stratification in natural water bodies. However, if the wind speed is high enough, strong forced mixing occurs, which leads to an isothermal water temperature. During the night, the most important forcing term is long-wave radiative cooling, which triggers the growth of a mixing layer starting from the water-atmosphere interface. Depending on the weather, the conditions at the side boundaries of the water body, and the size of the water surface, the water temperature behaviour in shallow waters can be very dynamic and complex.

Numerous models have been presented in the literature to describe the thermal behaviour of water bodies. The most intensively studied are the one-dimensional models, which can in fact be subdivided into two types (Harleman 1982): diffusion models, which describe the temperature profile of the water in detail (e.g. Losordo and Piedrahita 1991; Jacobs et al. 1997); and integral energy models, which describe the water temperature uniformly (e.g. DeBruin 1981). For most applications, information about the temperature behaviour in certain water layers is required. For example, for entomological applications, the water temperature in a very shallow layer at the top of the water body is important, while in certain fish pond applications, such as the breeding of flatfish, the temperature at the bottom of a pond is important (Tibbs and Galat 1998). In these cases, the diffusion models are more suitable as they provide a detailed description of the water temperature with depth.

The objectives of the present study were firstly to extend an existing one-dimensional atmosphere/water model to simulate the behaviour of the diurnal water temperature cycle in relatively very small water bodies. The model we used is adopted from an earlier study by Jacobs et al. (1997). The second objective was to perform an outdoor experiment to verify the model in different atmospheric conditions throughout the seasons.

\section{Materials and methods}

\section{Experimental set-up}

Wageningen University operates a long-term meteorological observatory, the Haarweg Station, in the centre of the
Netherlands (latitude $51^{\circ} 58^{\prime} \mathrm{N}$, longitude $5^{\circ} 38^{\prime} \mathrm{W}$, altitude $7 \mathrm{~m}$ a.s.1.; http://www.met.wau.nl). This grassland region is covered mainly with perennial species of ryegrass (Lolium perenne L.) and rough bluegrass (Poa trivialis L.). The soil at the site is predominantly heavy basin clay resulting from the back-swamps of the Rhine river (Snel 2004).

Below, only instruments used in this study are described. An aspirated psychrometer was used to measure the air temperature, $T_{\mathrm{a}}$, and wet-bulb temperature, $T_{\mathrm{w}}$, at reference height $z_{\mathrm{r}}=1.5 \mathrm{~m}$. The wind speed $u$ was measured by a cup anemometer at reference height $z_{\mathrm{r}}=1.5 \mathrm{~m}$. The air temperature $T_{\mathrm{a}}(0.10 \mathrm{~m})$ was measured with a shielded Pt-100 thermometer at $0.10 \mathrm{~m}$ height. The total incoming shortwave radiation, $K_{\text {in }}$, was measured with an aspirated pyranometer (Kipp \& Zonen, model CM11; Delft, The Netherlands) at a height of $1.5 \mathrm{~m}$. Also at this height, the incoming diffusive short wave radiation, $K_{\text {dif }}$, is measured with an pyranometer (Kipp \& Zonen, model CM11) combined with a shadow ring (Kipp \& Zonen, model CM $121 \mathrm{~B} / \mathrm{C})$. The incoming direct beam short wave radiation, $K_{\text {dir }}$, is calculated by subtraction, $K_{\text {dir }}=K_{\text {in }}-K_{\text {dif. }}$. The incoming long-wave radiation, $L_{\text {in }}$, was measured with a pyrgeometer (Kipp \& Zonen, model CG 1) at a height of $1.5 \mathrm{~m}$.

To estimate the thermal stability of the atmosphere, the turbulent momentum and sensible heat fluxes were measured at a height of $3.5 \mathrm{~m}$ with a three-dimensional sonic anemometer-thermometer (3D Solent Res, model A1012R2; Gill Instruments, Lymington, UK).

Soil temperatures, $T_{\text {soil }}$, were measured by Pt-100 elements at depths of $0.05,0.10,0.20,0.50$ and $1.0 \mathrm{~m}$. The soil moisture content at depths of $0.01,0.10$ and $0.50 \mathrm{~m}$ were measured with a TDR (time domain reflectrometry) system (TDR 100, probe type CS 610; Campbell Scientific, Loughborough, UK). The soil moisture results were used to obtain a reliable estimate of the actual heat conductivity of the soil. The soil heat flux was measured by a heat plate (WS 31-Cp; TNO, Delft, The Netherlands) buried at a depth of $75 \mathrm{~mm}$.

In addition to the continuous station measurements, a detailed sub-experiment was carried out in and around a shallow artificial water body of still water throughout 2003 . At the observatory site, about $30 \mathrm{~m}$ west of the radiation instruments, a circular plastic box was dug into the soil in which the water experiments were carried out. The box has a diameter of $1.10 \mathrm{~m}$ and a depth of $0.375 \mathrm{~m}$. The bottom of the box was cut out and replaced by a thin plastic sheet in order to ensure good thermal contact between the water and the underlying soil. The side walls of the box are made of 3-mm-thick PVC, and it appeared that hardly any heat flux occurred through the side walls. In fact this also means that our water model can be thought of as a so-called 1-D problem. The box was initially filled with tap water to a 
depth of $0.250 \mathrm{~m}$. The water level in the box was kept constant and checked daily.

The measurement layout in the water body is summarised in Fig. 1. The surface of the water is $0.12 \mathrm{~m}$ below the mean surface level of the surrounding soil. A stable floating system was designed with a inverted "mast" to which small glasscoated thermistors (model Beta G22k7MCD8) were connected at depths of $1,18,66,128$ and $196 \mathrm{~mm}$. The thermistors have a diameter of $0.8 \mathrm{~mm}$. At the bottom of the water body, a heat soil flux plate is installed (TNO, model WS 31-Cp). Two thermometers (Pt100-elements) were buried in the soil at a depth of $50 \mathrm{~mm}$ below the bottom of the water body. The heat conductivity of the soil was measured at various depths and locations using a non-stationary hot needle technique (Heusinkveld et al. 1992). The light extinction coefficient was measured following the method of Kirk (1984), with two underwater light sensors (type
RA100; Bottemanne Weather Instruments, Amsterdam). The underwater extinction coefficient was monitored throughout the seasons.

Data from the fast response sonic system were sampled at $20 \mathrm{~Hz}$, and all other slow response meteorological instruments were sampled at $0.25 \mathrm{~Hz}$. Data were averaged at 30-min intervals and stored in data loggers for subsequent processing. For more details of the measurements, site and data processing, see Kraai (2004) and Jacobs et al. (2003).

\section{Model description}

The one-dimensional model is based on the energy budget (see upper panel in Fig. 2). Here, the driving force during daytime is the incoming short-wave radiation. Immediately at the water surface a fraction, $\beta$, of the net short-wave
Fig. 1 Schematic outline of the experimental layout around the artificial water body
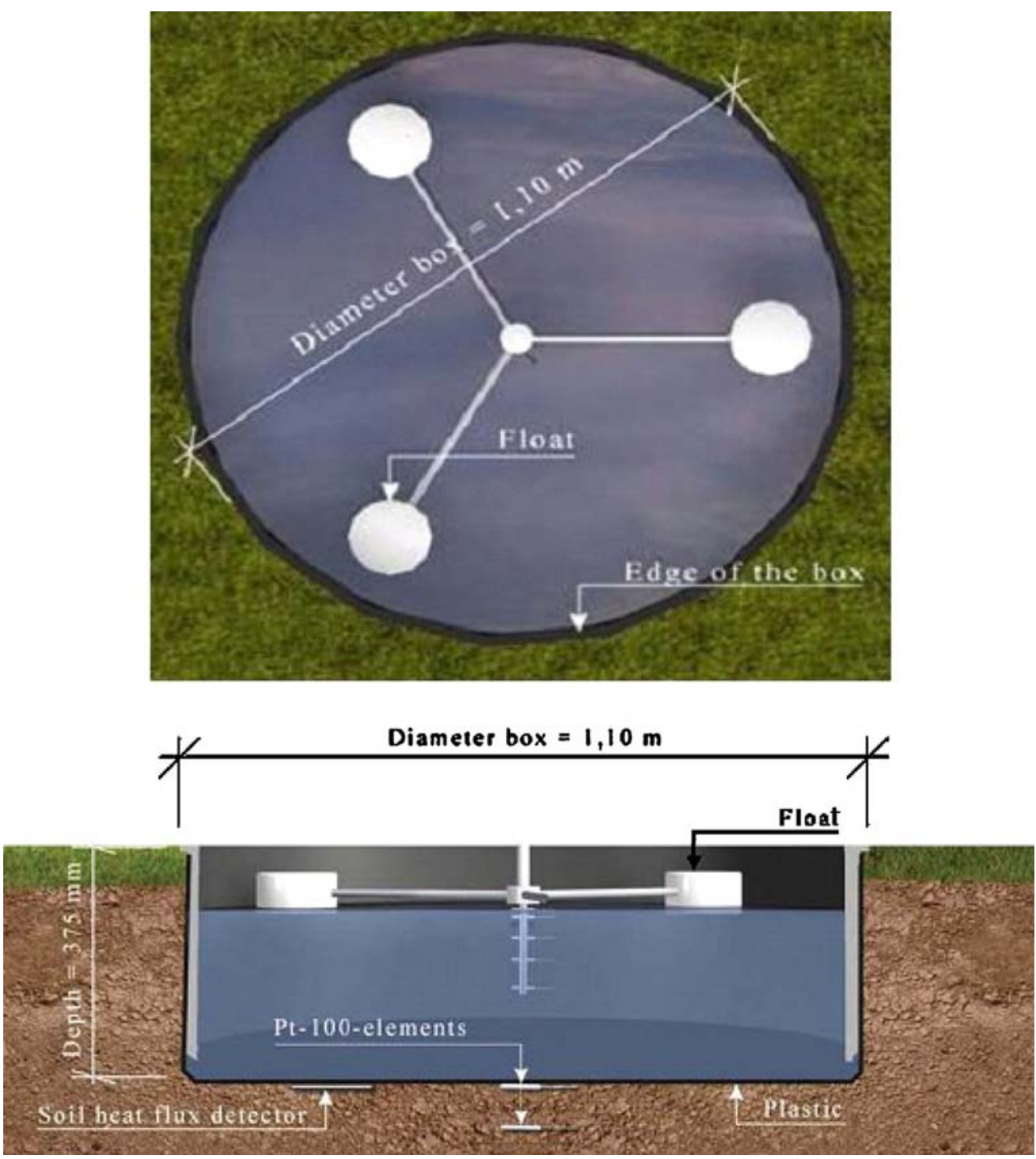
Fig. 2 Schematic overview of the main energy terms in a water body. Top panel Daytime situation, bottom panel nighttime situation

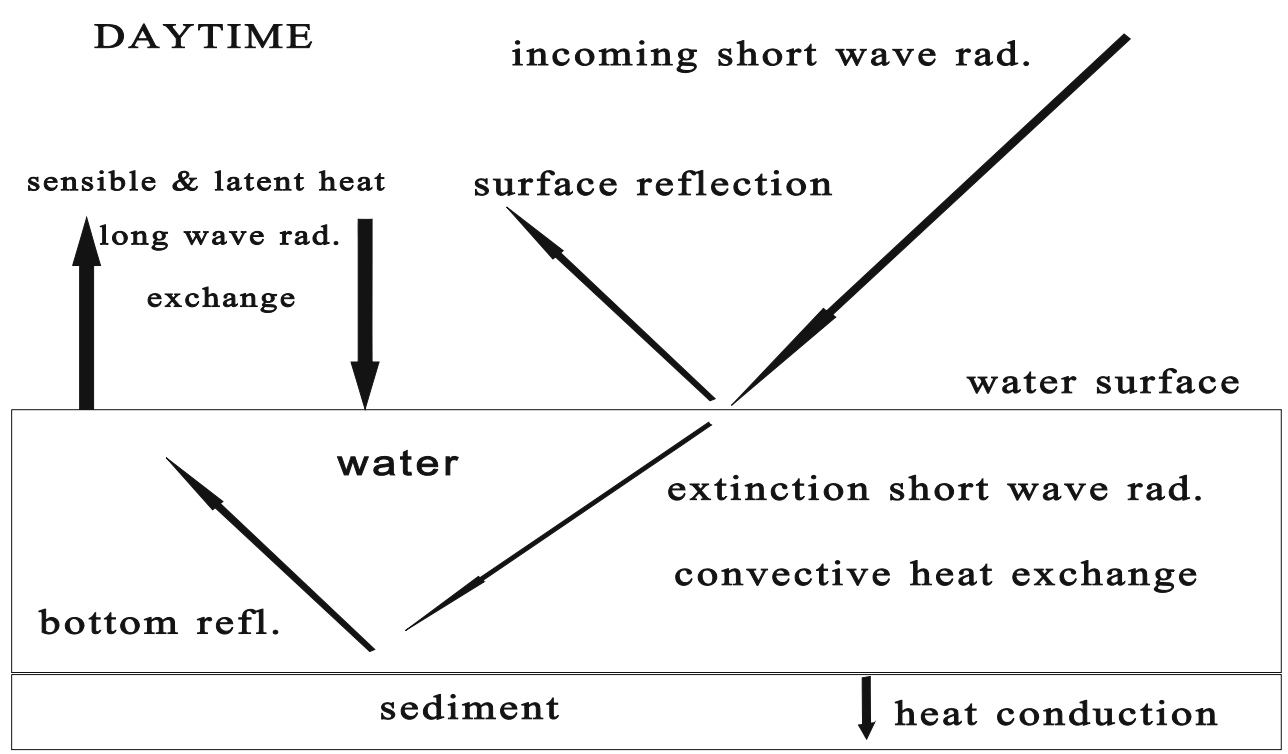

NIGHTTIME

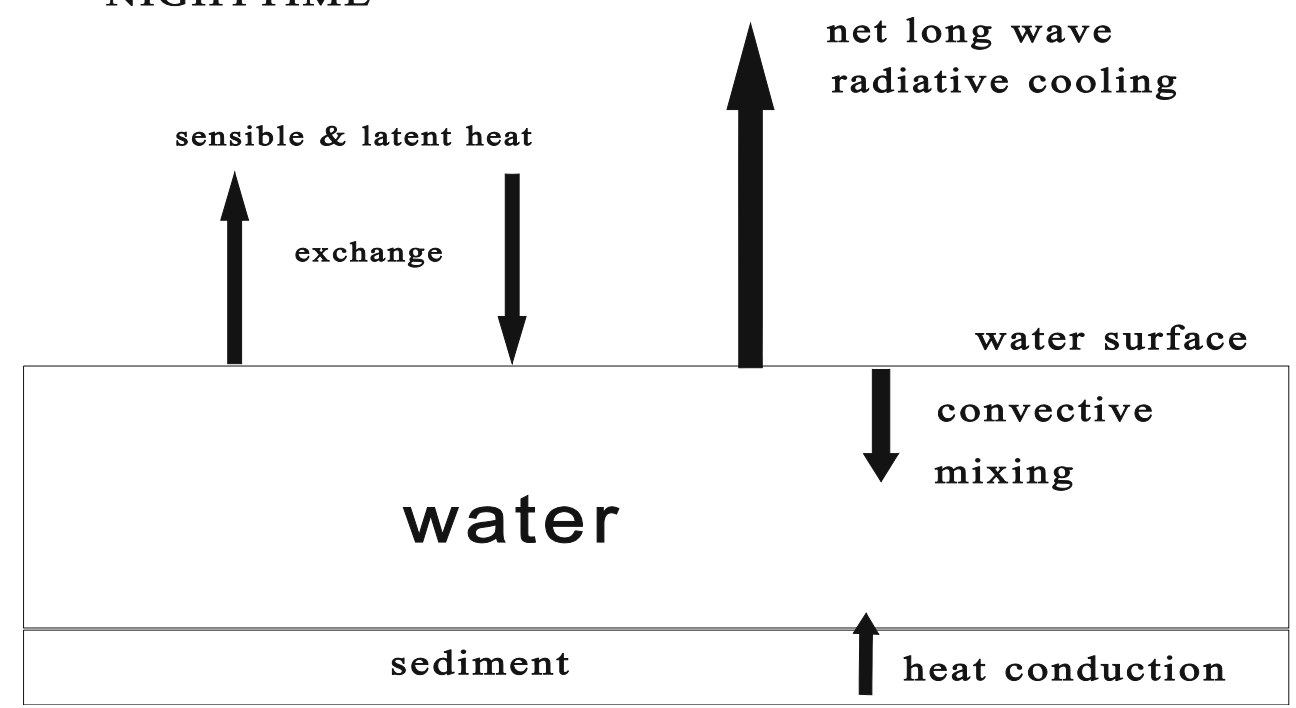

radiation is absorbed (Cathcart 1987; Jacobs et al. 1998a). Water is transparent to short-wave radiation, where absorption depends not only on the path length but also strongly on the turbidity of the water. Also at the water surface, exchange processes of long-wave (incoming and outgoing) radiation, sensible and latent heat take place (Cathcart 1987). For the first water layer with thickness $\delta$, the energy budget is:

$\Delta K+L_{n e t}-H-L E-G_{w}=c_{w} \delta \frac{\Delta T_{w}}{\Delta t}$

where, $\Delta K$ is the absorbed short-wave radiation in this layer, $H$ the sensible heat flux and LE the evaporation at the top of this layer, $G_{\mathrm{w}}$ the convective heat at the bottom of this layer, $c_{\mathrm{w}}$ the volumetric heat capacity of water, $\Delta T_{\mathrm{w}}$ the mean temperature change of this water layer, and $L_{\text {net }}$ the net long- wave radiation. For all other water layers the energy budget is:

$\Delta K-\Delta G_{w}=c_{w} \delta \frac{\Delta T_{w}}{\Delta t}$

$L_{\text {net }}$ at the water-air interface is calculated by taking the measured incoming long-wave radiation, $L_{\text {in }}$, minus the calculated outgoing long-wave radiation, $L_{\text {out }}$, at the airwater interface. The water temperature profile is calculated from the model. The uppermost water temperature is used to calculate the outgoing long-wave radiation at the airwater interface, $L_{\text {out }}$, according to Eq. 2 :

$L_{\text {out }}=\varepsilon_{w} \sigma T_{w}^{4}$ 
where $\varepsilon_{\mathrm{w}}(0.99)$ is the emissivity of the water and $\sigma(5.67$ $10^{-8} \mathrm{Wm}^{-2} \mathrm{~K}^{-4}$ ) is the Stefan Boltzmann constant. It must be noted that $L_{\text {in }}$ is corrected for the sky view factor, since the water body sees not only the sky but also a part of the side wall of the water box. In our case, the mean view factor is $150^{\circ}$, which means that the water body sees the sky for $150^{\circ}$ and the edges for $30^{\circ}$. Remember also that $G_{\mathrm{w}}$ at the lowest layer is the sediment heat flux.

The extinction of the incoming solar radiation in the water is described by Lambert-Beer's law (Cathcart 1987). The absorbed short-wave radiation in the aquatic surface layer, $n=1$, equals:

$\Delta K(n=1)=K_{\text {in }}(1-\alpha)\left[\beta+(1-\beta)\left(1-e^{-\frac{\varepsilon \delta}{x x}}\right)\right]$

and in all other water layers, $n>1$ :

$\Delta K(n)=K_{i n}(1-\alpha)(1-\beta) e^{\frac{-\varepsilon(n-1) \delta}{x x}}\left(1-e^{\frac{-\varepsilon \delta}{x x}}\right)$

where, $K_{\text {in }}$ is the incoming short-wave radiation at the water surface, $\alpha$ the albedo at the water surface, $\varepsilon$ the radiation extinction coefficient in the water, $\mathrm{xx}$ the correction factor for the actual path length (Höhne 1954; Stefan et al. 1983) depending on solar height and ratio of the direct and diffusive solar radiation, $\beta$ the amount of short-wave radiation immediately absorbed in the first layer (taken as $45 \%$ of the incoming short-wave radiation at the water surface; Orlob 1983; Octavio et al. 1977). The behaviour of the albedo of water, $\alpha$, is complex and depends on the solar elevation (so-called Fresnel albedo), on the diffusive component of the irradiation, and on the condition of the water surface. In the present study, the solar elevation was calculated and the Fresnel albedo, $\alpha_{\text {dir }}$, for the direct irradiation was estimated according to Graham Cogley (1979):

$\alpha_{d i r}=0.5\left[\frac{\sin ^{2}\left(\frac{\pi}{2}-e-r\right)}{\sin ^{2}\left(\frac{\pi}{2}-e+r\right)}+\frac{\tan ^{2}\left(\frac{\pi}{2}-e-r\right)}{\tan ^{2}\left(\frac{\pi}{2}-e+r\right)}\right]$

where $e$ is the solar elevation and $r$ is the refraction angle. For the diffusive radiation, a constant albedo of $\alpha_{\mathrm{dif}}=0.06$ was used (Graham Cogley 1979). The total reflection coefficient was calculated as follows:

$\alpha=f \alpha_{d i r}+(1-f) \alpha_{d i f}$

where $f$ is the fraction of the direct radiation and equals:

$f=\frac{K_{d i r}}{K_{\text {in }}}$

It is interesting to note that if no diffusive irradiation is available, the fraction $f$ can also be calculated by using the scheme established by DeJong (see e.g. Jacobs and van Pul 1990).
The transport of turbulent latent heat, $L E$, and sensible heat, $H$, from the water body towards the atmosphere, were parameterised by Arya (1988):

$L E=\rho L C_{E} u\left(z_{r}\right)\left(x\left(z_{r}\right)-x_{s}\right)$

$H=\rho c_{p} C_{H} u\left(z_{r}\right)\left(T_{a}\left(z_{r}\right)-T_{s}\right)$

where $\rho\left(\mathrm{kg} \mathrm{m}^{-3}\right)$ is air density; $L\left(\mathrm{~J} \mathrm{~kg}^{-1}\right)$ latent heat for vaporisation; $C_{\mathrm{E}}$ and $C_{\mathrm{H}}$ are water vapour and sensible heat exchange coefficients, respectively; $u\left(\mathrm{~m} \mathrm{~s}^{-1}\right)$ is wind speed at reference height $z_{\mathrm{r}} ; c_{\mathrm{p}}\left(\mathrm{J} \mathrm{kg}^{-1} \mathrm{~K}^{-1}\right)$ is the specific heat capacity of air; $x\left(\mathrm{~kg} \mathrm{~kg}^{-1}\right)$ is specific humidity; and index $s$ refers to the water surface. In the present study, the turbulent exchange coefficients are chosen to be (Mascart et al. 1995):

$C_{E}=C_{H}=C_{D N} F_{H}$

where, $F_{\mathrm{H}}$ is the stability correction factor, and $C_{\mathrm{DN}}$ the drag coefficient of the grass cover under neutral conditions, as defined by (Mascart et al. 1995):

$C_{D N}=\frac{\kappa^{2}}{\left(\ln \frac{z_{r}}{z_{o}}\right)^{2}}$

where, $\kappa(0.4)$ is Von Karman's constant and $z_{\mathrm{o}}(\mathrm{m})$ is the roughness length of the grass cover.

Within the water body, heat exchange occurs by convection and conduction. In the present model, it is assumed that no mean water flow is allowed, but that mixing is influenced by water density stratification and the wind component at the air-water interface (Bloss and Harleman 1979). The convective heat transport is taken as:

$G_{w}(z)=-\rho_{w} c_{w} K_{w}(z) \frac{\Delta T_{w}}{\Delta z}$

where $K_{\mathrm{w}}(z)$ is a complex function of the water surface friction velocity and $w^{*}$ is the depth, $z$, in the water and the density stratification in the water, expressed by the water Richardson number, $R i_{\mathrm{w}}$. In the model, the turbulent heat conductivity as suggested by Henderson-Sellers (1984) is used:

$K_{o, z}(z)=\frac{w^{*}}{30 k^{*}} e^{-k^{*} z}$

along with the stratification corrections suggested by Sundaram and Rehm (1973):

$K_{w}(z)=\frac{K_{o, w}(z)}{1+\sigma_{1} R i_{w}(z)}$

where $k^{*}$ and $\sigma_{1}$ represent an empirical function and a constant, respectively, and the water Richardson number, $R i_{\mathrm{w}}$, equals:

$R i_{w}(z)=\frac{a_{w} g z^{2} \Delta T}{w^{* 2} \Delta z}$ 
where, $g$ is gravity and $a_{\mathrm{w}}$ is the expansion coefficient for water, taken from Sundaram and Rehm (1973):

$a_{w}=1.5 \cdot 10^{-5}(\bar{T}-277)-2 \cdot 10^{-7}(\bar{T}-277)^{2}$

The surface friction velocity at the water surface, $w^{*}$, is suggested to be (Henderson-Sellers 1984):

$w *=\sqrt{\frac{\rho_{a} C\left(z_{r}\right) u^{2}\left(z_{r}\right)}{\rho_{w}}}$

where, $C\left(z_{\mathrm{r}}\right)(0.001)$ is the drag coefficient for a large water surface (Arya 1988). At the bottom of the circular water body, exchange of heat with the underlying soil occurs via conduction. The measured soil heat conductivity is taken as the lowest boundary condition.

At night, long-wave radiative cooling at the surface of the water body is the driving force (see bottom panel in Fig. 2). A decrease of the top temperature increases the water density in that layer, which is responsible for the growth of a mixing layer of uniform density. In the course of the night the temperature of the mixing layer decreases gradually and, as a consequence, the depth of the mixing layer also increases.

If it rains, it is assumed that the raindrops, as a first guess, have the same temperature as the wet bulb temperature, $T_{\mathrm{w}}$, of the ambient air at screen height $(1.5 \mathrm{~m})$. It is also assumed that, during a rain event, the uppermost water layer is affected by cooler or warmer rain drops. Thus, in the upper water layer, an additional energy, $Q_{\text {rain }}$, must be inserted, which equals:

$Q_{\text {rain }}=c_{w} R\left(T_{w}-T_{w a}\right)$

where $R$ is the precipitation intensity in $\left(\mathrm{m} \mathrm{s}^{-1}\right)$.

Equations $1 \mathrm{a}$ and $1 \mathrm{~b}$ are solved numerically using an explicit computation scheme. The number of water layers is $n=10$, which corresponds to a mean thickness of $25 \mathrm{~mm}$. To fulfill the numerical stability condition, a time step of $10 \mathrm{~s}$ is taken (Pantankar 1980).

\section{Results and discussion}

The response of the water temperature to meteorological conditions throughout the seasons was investigated in spring, summer and autumn. First, 3 consecutive days in spring (14, 15 and 16 April 2003) with fine weather and low wind speed $\left[u(1.5 \mathrm{~m})<3.5 \mathrm{~m} \mathrm{~s}^{-1}\right.$, where $u(1.5 \mathrm{~m})$ is wind speed at $1.5 \mathrm{~m}$ height] were selected in order to analyse the effect of weather in spring on the behaviour of the water temperature at various depths. The top panel of Fig. 3 illustrates the most important environmental variables during these days. The bottom panel of Fig. 3 shows the results of measurements of water temperature and air temperature, $T_{\mathrm{a}}$, at $1.5 \mathrm{~m}$, and the soil temperature at a depth of $50 \mathrm{~mm}$, together with the simulation results. The soil temperature at $50 \mathrm{~mm}$ is the soil temperature at the undisturbed reference location of the observatory. The radiation extinction coefficient in the water was $\varepsilon=8 \mathrm{~m}^{-1}$ during this period. Figure 3 shows a clear stratification starting after sunrise for the measured water temperatures, $T_{\text {wa }}$, at all levels. When cooling begins in the afternoon, a slow but clear mixing layer starts from the surface of the water. Also, it can be seen that a complete well mixed layer exists late at night. From the wind measurements shown in Fig. 3, it can be observed that the wind speed was low $\left[u(1.5 \mathrm{~m})<3.5 \mathrm{~m} \mathrm{~s}^{-1}\right]$ throughout the entire period and consequently could not have caused a well forced convective mixing within the water body.

The temperature model simulations, $T_{\mathrm{mo}}$, mimic well the measured water temperatures during daytime. During the night, however, dissimilarity between model and experiment is evident in the higher levels of nocturnal cooling $\left[T_{\mathrm{mo}}(0.02 \mathrm{~m})\right.$ and $\left.T_{\mathrm{mo}}(-0.13 \mathrm{~m})\right]$ of about $1^{\circ} \mathrm{C}$. Notice also that the air temperature, $T_{\mathrm{a}}(1.5 \mathrm{~m})$, always exceeds the water temperature during this period of the year. This means that the surface of the surrounding grass cover usually has a higher temperature than the water surface. In contrast, the soil temperature at $50 \mathrm{~mm}$ depth, $T_{\text {soil }}(-50 \mathrm{~mm})$, is nearly
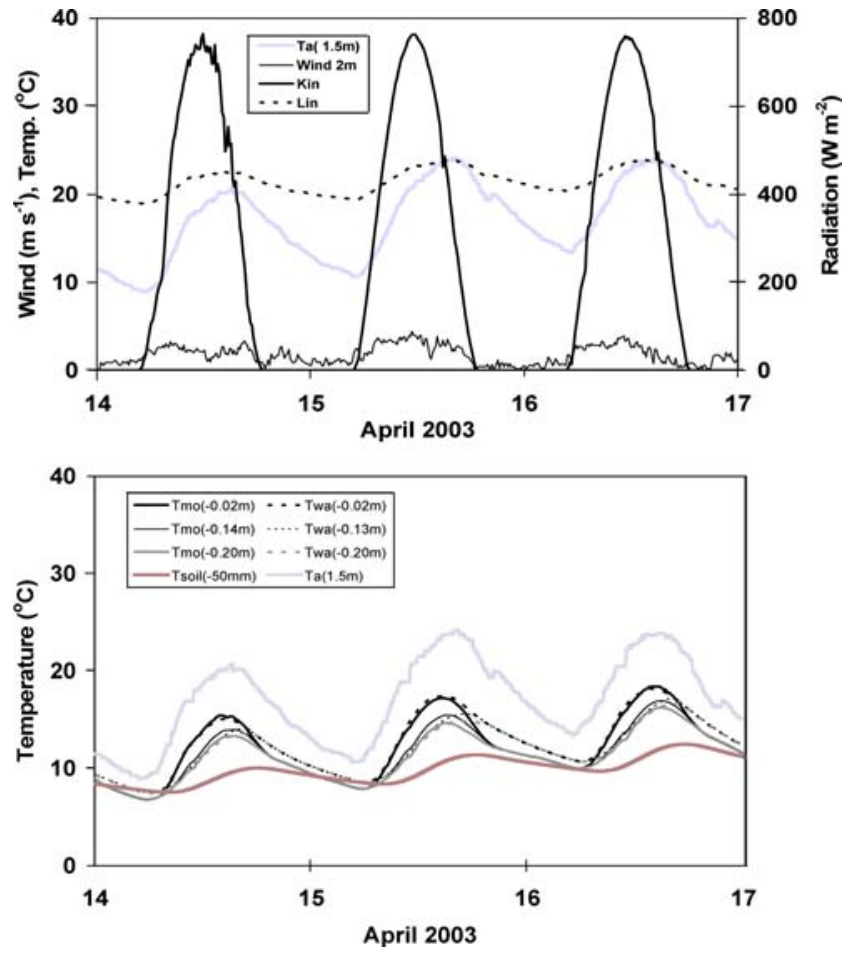

Fig. 3 Top panel Relevant environmental conditions during a period in spring (14-16 April 2003). $T_{\mathrm{a}}$ Air temperature, $K_{\text {in }}$ total incoming short-wave radiation, $L_{\text {in }}$ measured incoming long-wave radiation. Bottom panel Observed (dashed lines) and simulated (solid lines) water temperatures, along with the air temperature $T_{\mathrm{a}}$ at $2 \mathrm{~m}$ height and the undisturbed soil temperature $T_{\text {soil }}$ at $50 \mathrm{~mm}$ depth 
always lower than the water temperature. The soil temperature slowly tends towards a higher level due to spring heating of the soil and due to the large heat capacity of the soil.

A second period of 3 days in summer (4, 5 and 6 August 2003) with low wind conditions and with a level of incoming short-wave radiation about the same as in the selected spring period was selected. The most relevant environmental variables are plotted in the top panel of Fig. 4. The radiation extinction coefficient in the water was $\varepsilon=12 \mathrm{~m}^{-1}$ during this period. The measurement results and model simulations are plotted in the bottom panel of Fig. 4. The results from Fig. 4 show that the general pattern agrees with that found in spring. However, some differences can be seen. First, as must be expected, the air, soil and water temperatures are much higher during this period of the year than in spring. Second, the water temperature at the waterair interface lies close to the air temperature during daytime. At night, however, all water temperatures are much higher than the air temperature. As a consequence it must be expected that, during the night, the water body will lose energy by sensible heat as well as by evaporation.

The simulated water temperatures agree much better with the measured water temperatures during this period. A
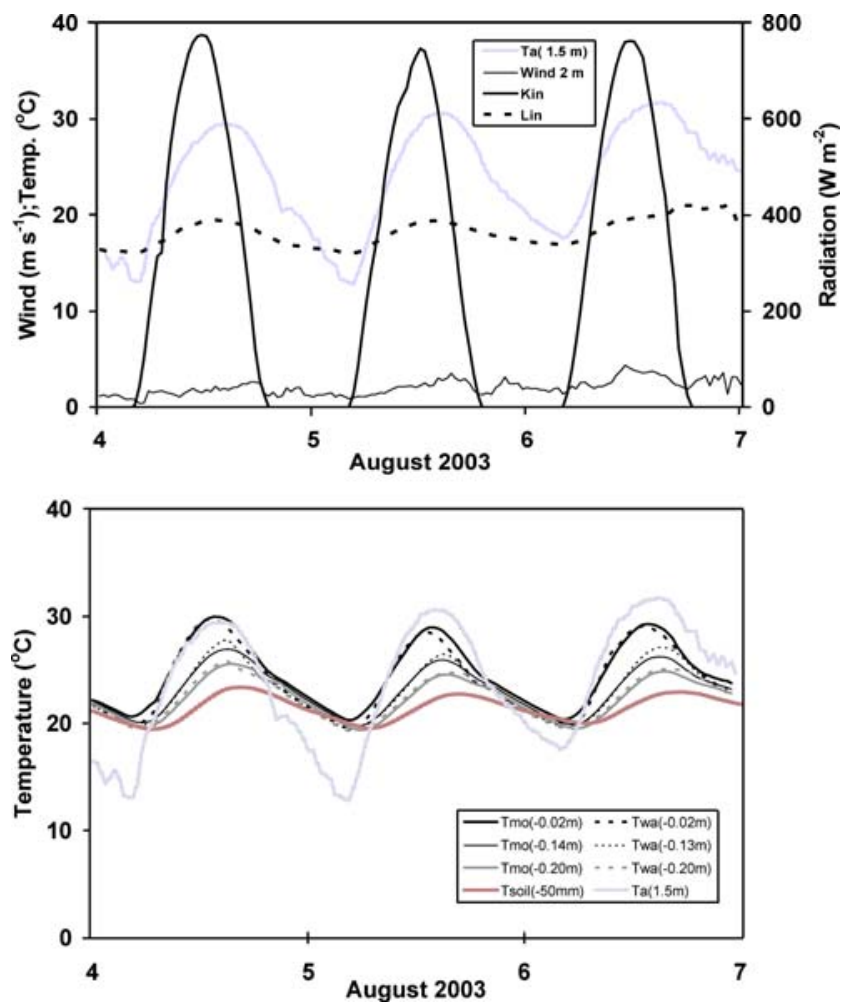

Fig. 4 Top panel Relevant environmental conditions during a period in summer (4-6 August 2003). Bottom panel Observed (dashed lines) and simulated (solid lines) water temperatures, along with the air temperature $T_{\mathrm{a}}$ at $1.5 \mathrm{~m}$ height and the undisturbed soil temperature $T_{\text {soil }}$ at $50 \mathrm{~mm}$ depth
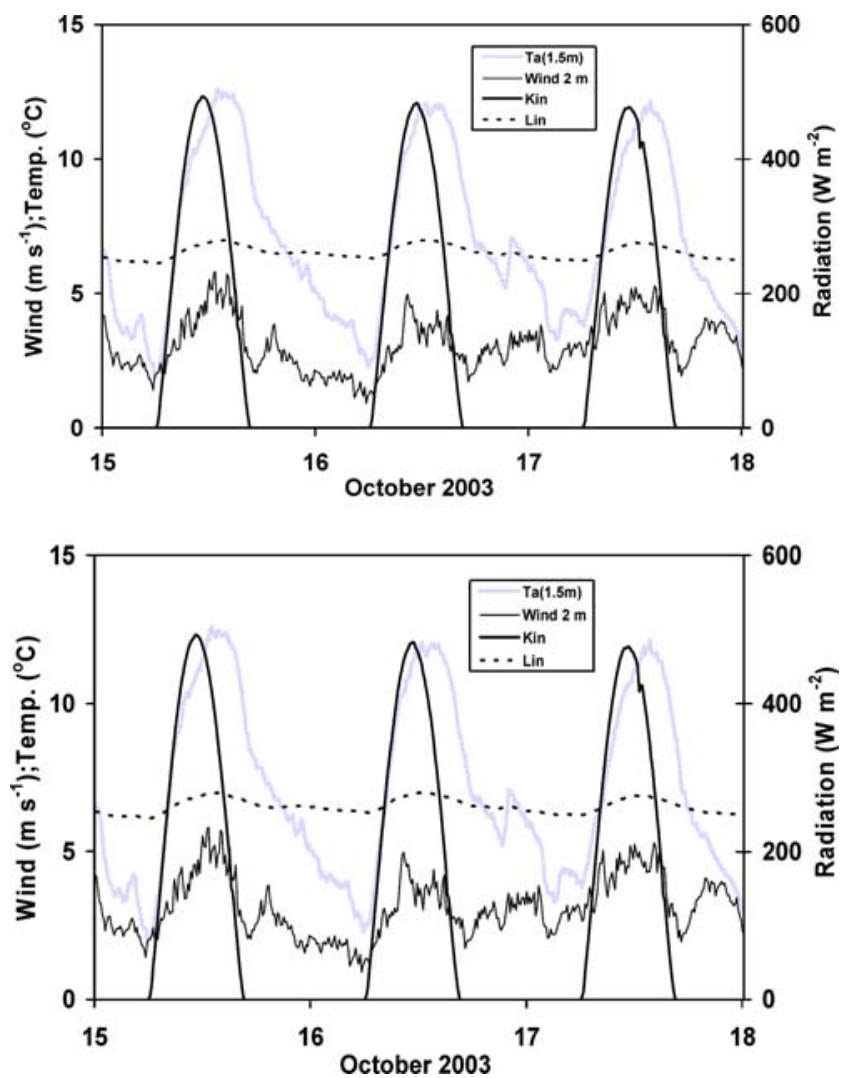

Fig. 5 Top panel Relevant environmental conditions during a period in autumn (15-17 October 2003). Bottom panel Observed (dashed lines) and simulated (solid lines) water temperatures, along with the air temperature $T_{\mathrm{a}}$ at $2 \mathrm{~m}$ height and the undisturbed soil temperature $T_{\text {soil }}$ at $50 \mathrm{~mm}$ depth

possible reason for this better agreement will be discussed below.

A third period of 3 days $(15,16$ and 17 October 2003) in autumn was selected. The most relevant environmental variables are plotted in the top panel of Fig. 5. The measurement results and model simulations are plotted in the bottom panel of Fig. 5. The radiation extinction coefficient in the water was $\varepsilon=20 \mathrm{~m}^{-1}$ during this period.

The behaviour of the soil temperature was interesting (Fig. 5). During this period of the year, the soil temperature is relatively high, which means that the soil contains a high amount of energy, which is released slowly to the atmosphere and, in our case, also to the water body. In fact, this means that the cooling of the water temperatures in autumn is slowed down by the heat capacity of the soil.

Another interesting phenomenon is the changes in air temperature behaviour throughout the seasons. In spring the air temperature is much higher than the water temperature, while in summer and autumn the air and water temperatures are more or less equal. As will be shown later, the highest dynamics at the boundaries of the water body occur during spring. 
Figure 6 shows the fluxes of sensible heat, evaporation and soil heat in the sediment below the water body. From these results, it can be clearly concluded that the system dynamics are highest in spring and relatively low in all other seasons. In spring the air is relatively dry, which enhances the evaporation flux from the water body during daytime as well as during nighttime. In addition, the water body temperature during spring is relatively low, which causes a sensible heat flux opposite to the evaporation flux. During this season, only the sediment heat flux shows a daily pattern around zero. We suspect that the reason the agreement between model and experimental results is
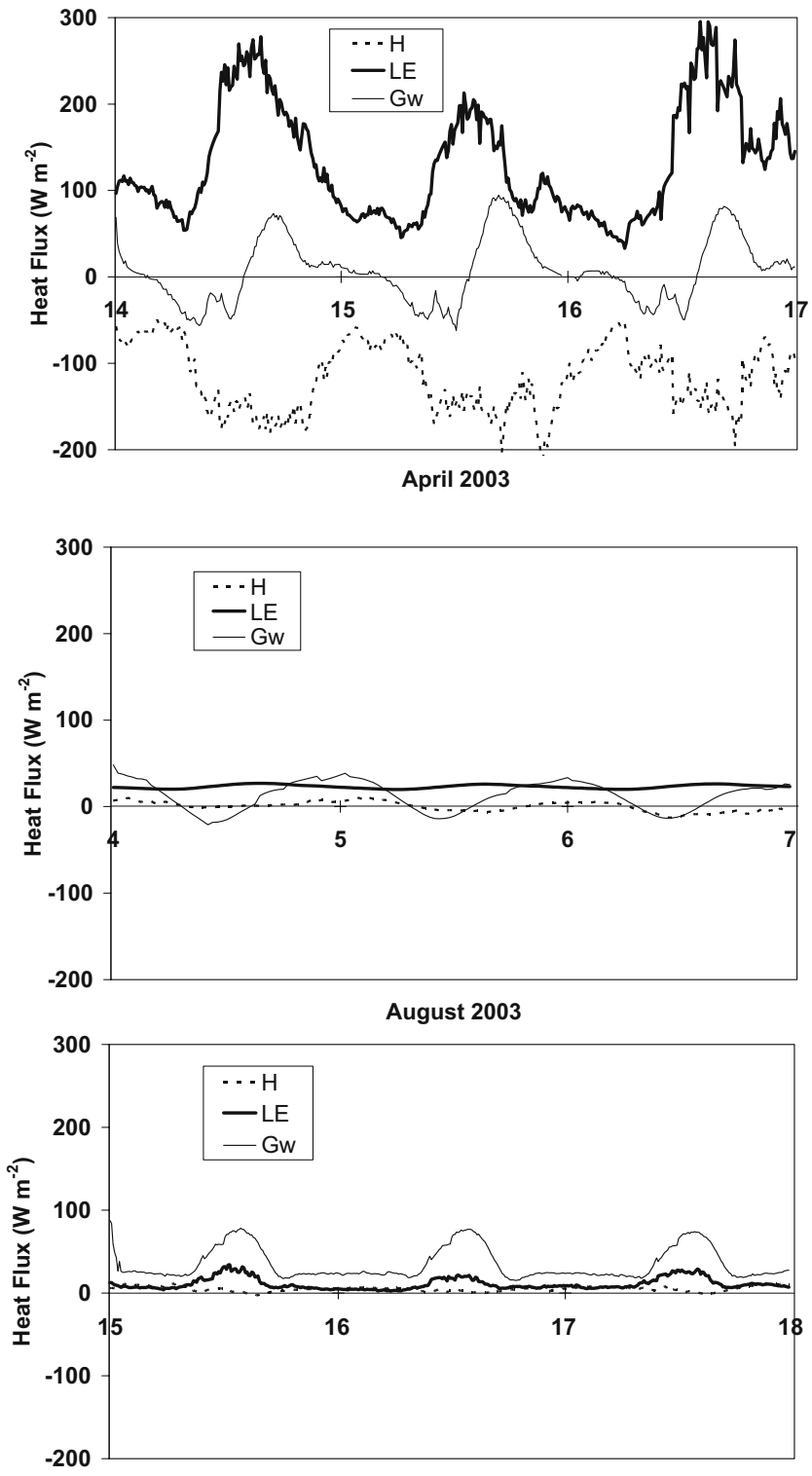

October 2003

Fig. 6 Fluxes of evaporation and sensible heat at the wateratmosphere interface and the sediment heat flux at the water-sediment interface in spring (top panel), summer (middle panel) and autumn (bottom panel) lowest in spring is because the dynamics of the fluxes is highest in spring.

In August, the water temperature rises to a higher level, causing a more or less constant evaporative flux. In contrast, the sensible heat flux above the water shows a small daily cycle opposite to that of the daily sensible heat flux cycle above vegetation; during the daytime modest heating by the ambient air $\left(T_{\mathrm{a}}>T_{\mathrm{w}}\right)$, with a release of sensible heat during the night $\left(T_{\mathrm{a}}<T_{\mathrm{w}}\right)$. The sediment heat flux during this period shows a clear daily cycle whereby the sediment is heated during daytime and cooled during nighttime.

In autumn, there is a relatively large sediment heat flux from the underlying soil sediment, which heats the water throughout the whole day and consequently delays seasonal cooling. In addition, it can be observed (Fig. 5) that in autumn the water temperature at the water-atmosphere interface is higher then the air temperature all day. This means an all-day cooling of the water at the water air interface. This process is clearly reflected in the results presented in the bottom panel of Fig. 6 .

An additional fourth period (4 June 2003) with a rain event during daytime was selected in order to investigate the effect of precipitation on water temperature. The top panel of Fig. 7 shows the measured and modelled water temperatures along with the air temperature and the rain events; the bottom panel shows the various fluxes.

During the rain event, a clear drop in the air temperature occurs and, in addition, a small drop in the uppermost water temperature. However, no great effect of this rain event of about $5 \mathrm{~mm}$ in $20 \mathrm{~min}$ can be observed. The energy drop caused by the cold raindrops, $Q_{\text {rain }}$ (see Eq. 9), was $80 \mathrm{~W}$ $\mathrm{m}^{-2}$, while during the rain event the incoming short-wave radiation was $400 \mathrm{~W} \mathrm{~m}^{-2}$. The energy drop caused by the raindrops is relatively small compared to the short-wave irradiation, hence for this particular rain event no large effect on the water temperature can be expected. Also, it is important to note that, in our case, the heat capacity of the water body, which is per unit of the water surface, is about $1.2 \times 10^{6} \mathrm{~J} \mathrm{~m}^{-2} \mathrm{~K}^{-1}$, which is very high and reduces any effect of the rain on water temperature. The same result was found earlier by Evens et al. (1998) in a river study. However, in a study on small water puddles caused by the hoof prints of animals, and which are often breeding places for malaria larvae, we found large effects of rain events (K.P. Paaijmans, A.F.G. Jacobs and B.G. Heusinkveld, manuscript submitted). However, in this latter case the water puddles are very small $(\varnothing=0.16 \mathrm{~m})$ and very shallow (0.04 m depth).

From the bottom panel in Fig. 7, it can be observed that only the evaporation flux is somewhat affected by the rain event; hardly any effect on the sensible heat and soil heat flux in the sediment can be observed. 

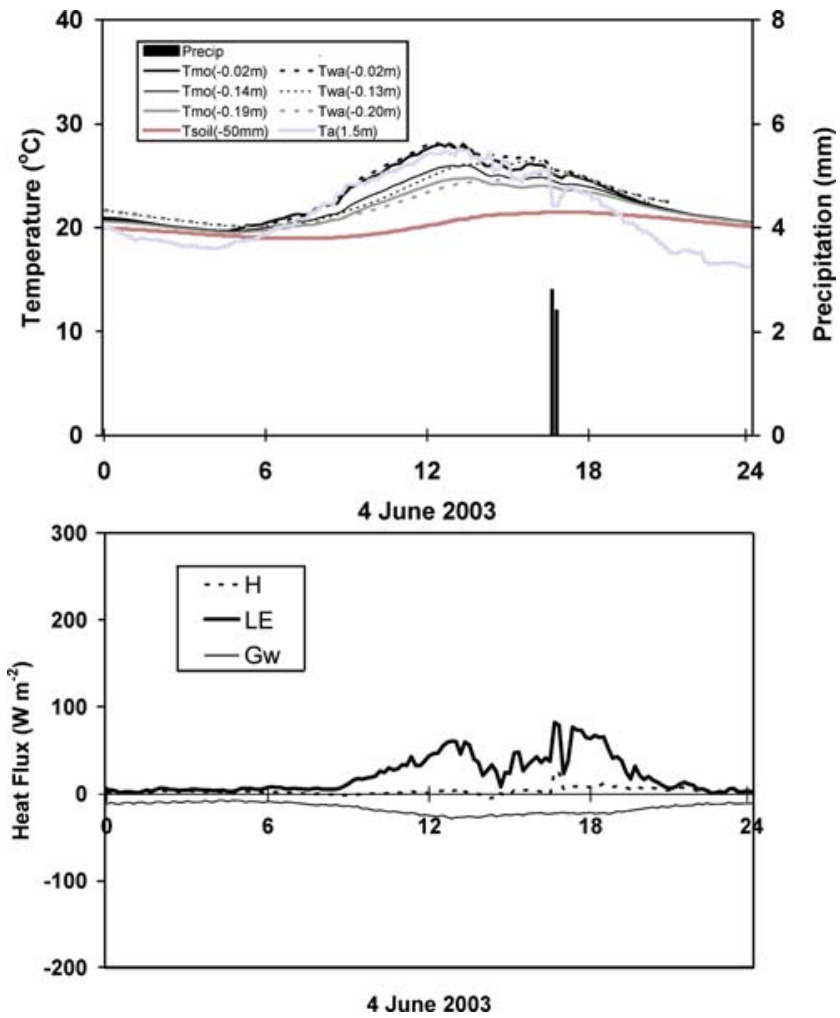

Fig. 7 Top panel Relevant environmental conditions during a rain event (4 June 2003). Bottom panel Observed (dashed lines) and simulated (solid lines) water temperatures, along with the air temperature $T_{\mathrm{a}}$ at $1.5 \mathrm{~m}$ height and the undisturbed soil temperature $T_{\text {soil }}$ at $50 \mathrm{~mm}$ depth

Few past studies have examined very small water bodies of the size we used in our experiments. We ourselves did two comparable studies in the past. One (Jacobs et al. 1997) focussed on a larger natural water body with a diameter of $6 \mathrm{~m}$ and a water depth of $0.35 \mathrm{~m}$. Water plants grew near the edges of the water body, and the vegetation around the water body in this natural bog area comprised tussocks of relatively long grasses (height $\approx 0.45 \mathrm{~m}$ ). The experiments were executed during the summer months only. Generally, the pattern of the water temperatures measured in this water body was similar to the results from this study during the summer period. One difference, however, was that the daytime temperature gradient within the water was at least two-fold larger. The reason for this difference in temperature gradient is that the tussocks around the water body caused an effective sheltering from the wind, reducing turbulence just above the water surface and consequently reducing mixing within the water body.

The second study was of a so-called Class A evaporation pan (Jacobs et al. 1998b). This pan has a diameter of $1.2 \mathrm{~m}$ and a height of $0.25 \mathrm{~m}$. The evaporation pan was placed on the grass cover of our observatory, which means that the wind speed was seriously disturbed by the edges of the pan and enhanced the turbulence above the water. The result of this extra turbulence was that the water body was always well mixed and the temperature of the water body behaved more or less uniformly. The same homogeneous water temperature result is found in large lakes and in large water reservoirs (e.g. Smith 1979). In these studies, the wind has a long free fetch; consequently, no wind sheltering or wind blocking by the boundaries of the lake or water reservoir can affect the wind profile above these large water bodies. For large water bodies such as lakes and water reservoirs, turbulence in the water is strongly dependent on wind speed as well as on the wave spectrum, whereas the wave spectrum is strongly fetch dependent (Arya 1988).

In the German literature, there is an old, but nice study on small water bodies (Hohne 1954). It was published in the former DDR republic, however, and nowadays it is difficult to obtain a copy of this study. It is a theoretical study presenting qualitative figures only of the course of the water temperature at various depths. During daytime, these qualitative results roughly agree with our results; however, during the night no good mixing was observed, which is quite different from the results of our study.

There is an interesting study from Losordo and Piedrahita (1991) executed in aquaculture ponds. These ponds show some stratification during very calm days. The ponds in their study are quite large (up to 10 ha with a depth of about $2 \mathrm{~m}$ ) and had an effective fetch of approximately $65 \mathrm{~m}$, which means that, during daytime, only under very low wind conditions could stratification be observed. The difference between Losordo and Piedrahita's study and the present study is that our water body is orders of magnitude smaller. That means that we have no undisturbed wind fetch and consequently no equilibrium between wind speed above the water and the surface speed of the underlying water surface. For our experiments it means that the degree of turbulence just above the water body is defined by the edge type (step upward or step downward) and by wind sheltering the vegetation around the water body.

\section{Conclusions}

A year-round experiment was conducted in a small water body. An existing water model was extended to simulate the water temperatures and the fluxes at the boundaries. The results obtained in different seasons are discussed. Moreover, the effect of a rain event on the water temperature has been analysed. The following main conclusions can be drawn from the experiments and the simulations:

1 During daytime a clear stratification in the water exists under relatively low wind conditions.

2 During nighttime a clear mixed layer starts to grow from the atmosphere-water interface. 
3 A clear seasonal effect can be observed in which the sediment heat flux plays a dominant role. In spring the heating of the water body is delayed, while in autumn cooling is delayed.

4 The model simulations mimic our experimental observations reasonably well. The largest deviations between model and measurement occur during nighttime, especially in spring. A possible reason might be that, particularly in spring, the dynamics of the fluxes at the boundaries are largest.

5 Because of the high heat capacity of the water body, hardly any effect of rain events on water temperatures can be observed.

\section{References}

Ames WF (1977) Numerical methods for partial differential equations. Academic, New York

Arya SP (1988) Introduction to micrometeorology. Academic, SanDiego

Bloss G, Harleman RF (1979) Effect of wind-mixing on the thermocline formation in lakes and reservoirs. Techn Rep 249, Ralph M. Parson Laboratory, MIT, Cambridge MA

Bouman BAM, Van Laar HH, Wang Zhaoqian (eds) (1993) Agroecology of rice-based cropping systems. SARP Re Proc

Cathcart TP (1987) Heat transfer and temperature prediction in small fresh water ponds. PhD thesis, University of Maryland, Dept of Agriculture Engineering

DeBruin HAR (1981) Temperature and energy balance of a water reservoir determined from standard weather data of a land station. J Hydrol 59:261-274

De Meester L, Declerck S, Stoks R, Louette G, Van De Meuter F, De Bie T, Michels E, Brendonck L (2005) Ponds and pools as model systems in conservation biology, ecology and evolutionary biology. Aquatic Conserv Mar Freshwater Ecosyst 15:715-725

Evens EC, McGregor GR, Petts GE (1998) River energy budgets with special reference to river bed processes. Hydr Processes 12:575-595

Graham Cogley J (1979) The albedo of water as a function of latitude. Monthly Weather Rev 107:775-781

Harleman DRF (1982) Hydrothermal analysis of lakes and reservoirs. J Hydr Division, ASCE 108:302-325

Henderson-Sellers B (1984) Engineering limnology. Pitman Advanced Publishing Program, Boston MA

Heusinkveld BG, Van Loon W, Jansen A (1992) Outdoor technique to estimate the soil heat conductivity for atmospheric use. WMO/ TD No 642:205-207

Höhne W (1954) Experimentelle und Mikroklimatische Untersuchungen an Kleingewässern. Abh. Met. D. DDR 4, Nr. 26
Jacobs AFG, Van Pul WAJ (1990) Seasonal changes in the albedo of a maize crop during two seasons. Agric For Meteorol 49:351-360

Jacobs AFG, Jetten TH, Lucassen DC, Heusinkveld BJ, Nieveen JP (1997) Daily temperature variation in a natural shallow water body. Agric For Meteorol 88:269-277

Jacobs AFG, Heusinkveld BG, Nieveen JP (1998a) Temperature behavior of a natural shallow water body during a summer period. Theor Appl Climatol 59:121-127

Jacobs AFG, Heusinkveld BG, Lucassen DC (1998b) Temperature variation in a class A pan. J Hydrol 206:75-83

Jacobs AFG, Heusinkveld BG, Holtslag AAM (2003) Carbon dioxide and water vapour flux densities over a grassland area in The Netherlands. Int J Climatol 23:1663-1675

Jetten TH, Takken W (1994a) Impact of climate change on malaria vectors. Change 18:10-12

Jetten TH, Takken W (1994b) Anophelism without malaria in Europe: a review of the ecology and distribution of the genus Anopheles in Europe. Wageningen Agric University Papers 94.5

Kirk JTO (1984) Attenuation of solar radiation in scattering absorbing water; a simplified procedure for its calculation. Appl Optics 23:3737-3739

Kraai A (2004) Thermal stratification in a small water body at different weather conditions. MSc-thesis Wageningen University

Losordo TM, Piedrahita RH (1991) Modelling temperature variation and thermal stratification in shallow aquaculture ponds. Ecol Modelling 54:189-226

Mascart P, Noilhan J, Giordani H (1995) A modified parameterization of the surface flux-profile relations using different roughness length values for heat and momentum. Bound Layer Meteorol 72:331-344

Nicolet P, Biggs J, Fox G, Hodson MJ, Reynolds C, Whitfield M, Williams P (2004) The wetland plant and macroinvertibrate assemblages of temporary ponds in England and Wales. Biol Conserv 120:261-278

Octavio KA, Jirka GH, Harleman DRF (1977) Vertical transport mechanisms in lakes and reservoirs. Techn Rep 227, Ralph M Parsons Laboratory, Mass Inst Technology Cambridge MA

Orlob GT (1983) Models for stratified impoundments. In: Biswas AK (ed) Models for water quality management. McGraw-Hill, New York, pp 273-313

Pantankar SV (1980) Numerical heat transfer and fluid flow. Hemisphere, New York

Smith IR (1979) Hydraulic conditions in isothermal lakes. Freshwater Biol 9:119-145

Snel S (2004) Soil-atmosphere exchange of $\mathrm{CO}_{2}$. MSc Thesis, Wageningen University, Dept. Meteorology and Air Quality

Stefan HG, Cardoni J, Scheibe FR, Cooper CM (1983) Model of light penetration in a turbid lake. Water Res Res 19:157-167

Sundaram TR, Rehm RG (1973) The seasonal thermal structure of deep temperature lakes. Tellus 25:157-167

Tibbs JE, Galat DL (1998) The influence of river stage on endangered least terns and their fish prey in the Mississippi river (USA). Regulated Rivers Res Manage 14:257-266 